\title{
MOdel BASED SCHEDUling SCENARIO GENERATION
}

\author{
BLASKOVIC, B. \& RANDIC, M.
}

Abstract: This article deals with model based systems. Following the concepts from process algebra, formal model of the system is built. After that model is transformed to the predicate net and simulation program providing executable specification for the problem domain. Results are analyzed and discussed through scheduling scenario example.

Key words: model based systems, schedulling and planning, predicate transition petri nets , simulation, specification, verification
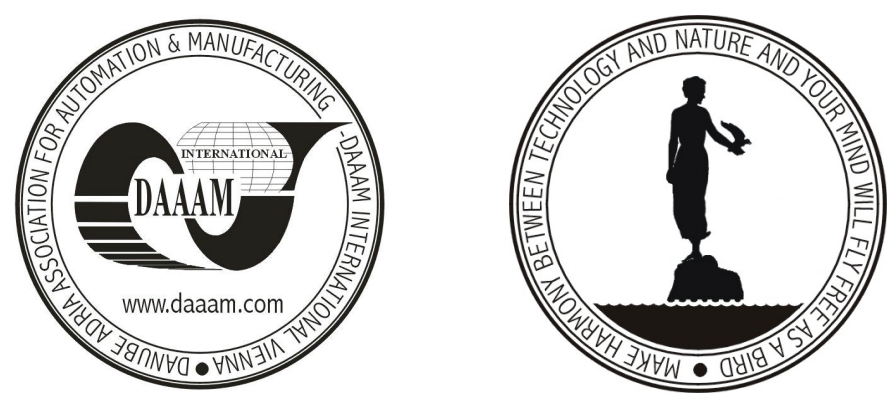

Authors' data: Prof. Dr. Blaskovic B.[runo], Ass. Prof. Randic M.[irko], Faculty of Electrical Engineering and Computing Zagreb, Croatia, bruno.blaskovic@fer.hr, mirko.randic@fer.hr

This Publication has to be referred as: Blaskovic, B. \& Randic, M. (2006). Model Based Scheduling Scenario Generation, Chapter 04 in DAAAM International Scientific Book 2006, B. Katalinic (Ed.), Published by DAAAM International, ISBN 3-901509-47-X, ISSN 1726-9687, Vienna, Austria

DOI: $10.2507 /$ daaam.scibook.2006.04 